\section{Efetividade da suplementação de sulfato ferroso na prevenção da anemia em crianças: revisão sistemática da literatura e metanálise}

\author{
Effectiveness of ferrous sulfate supplementation in \\ the prevention of anemia in children: a systematic \\ literature review and meta-analysis
}

\author{
Eficacia del suplemento de sulfato ferroso en \\ la prevención de la anemia en niños: revisión \\ sistemática de la literatura y metaanálisis
}

Francieli Cembranel 1

Camila Dallazen 1

David Alejandro González-Chica ${ }^{1}$

\footnotetext{
1 Universidade Federal de Santa Catarina, Florianópolis, Brasil.

Correspondência D. A. González-Chica Programa de Pós-graduação em Nutrição, Universidade Federal de Santa Catarina. Campus Universitário Trindade, Florianópolis, SC 88040-900, Brasil. david.epidemio@gmail.com
}

\begin{abstract}
This was a systematic review and meta-analysis of studies evaluating the effectiveness of ferrous sulfate supplementation in the prevention of anemia in children under five. The database search included PubMed, Scopus, LILACS, and SciELO. Articles published between 1980 and 2011 in Spanish, English, or Portuguese were included, using the keywords child, preschool, in fant, anemia, prevention, and iron supplementation. The authors selected 13 studies, which showed that regardless of dose and duration of supplementation, daily regimen was more consistently related to improvement in hemoglobin levels (pooled effect 0.56mg/dL, 95\%CI: 0.31 $0.81, p<0.001)$ as compared to weekly intervention (pooled effect $0.28 \mathrm{mg} / \mathrm{dL}$, 95\% CI: -0.22; 0.78, $p=0.273$ ). Iron supplementation was not associated with decreased prevalence of anemia, even with daily doses, and administration with other micronutrients did not bring additional benefits compared to the exclusive administration of iron supplement. Daily supplementation of ferrous sulfate was more effective than weekly doses in improving hemoglobin levels.
\end{abstract}

Anemia; Iron; Preschool Child; Dietary Supplements

\section{Resumo}

Revisão sistemática e metanálise de estudos que avaliaram a efetividade da suplementação de sulfato ferroso na prevenção da anemia em crianças menores de cinco anos de idade. Foram pesquisadas as bases PubMed, Scopus, SciELO e LILACS e incluídos artigos publicados entre 1980-2011 em espanhol, inglês ou português, utilizando os unitermos: criança, pré-escolar, lactente, anemia, prevenção, suplementação e ferro. Foram selecionados 13 estudos, que mostraram que independentemente da dose e do tempo de suplementação, o esquema diário foi mais consistente na melhoria dos níveis de hemoglobina (efeito combinado 0,56mg/dL, IC95\%: 0,31;0,81, $p<0,001$ ) do que o semanal (efeito combinado 0,28mg/dL, IC95\%: -0,22; 0,78, $p=0,273$ ). Não houve efeito da suplementação na redução da prevalência de anemia, mesmo com doses diárias, e a administração conjunta com outros micronutrientes não trouxe benefícios adicionais em comparação com a administração exclusiva do suplemento. A suplementação diária de sulfato ferroso mostrou-se mais efetiva do que doses semanais na melhoria dos níveis de hemoglobina.

Anemia; Ferro; Pré-Escolar; Suplementos Dietéticos 


\section{Introdução}

A anemia nutricional é definida pela Organização Mundial da Saúde (OMS) como a condição na qual o conteúdo de hemoglobina $(\mathrm{Hb})$ no sangue está abaixo dos níveis considerados normais para o sexo, faixa etária, estado fisiológico e altitude 1 . O motivo mais frequente é a deficiência de ferro, caracterizando a chamada anemia ferropriva ou ferropênica, que apresenta como causas principais o baixo consumo e/ou a baixa absorção do ferro dietético 1,2,3.

Em termos globais, a anemia por deficiência de ferro configura-se na principal endemia carencial do mundo e, segundo a OMS, estimase que esteja presente em aproximadamente $24,8 \%$ da população mundial, sendo as crianças em idade pré-escolar as mais afetadas $(47,4 \%) 4$. Essa doença resulta ainda mais preocupante ao considerar a prevalência da deficiência de ferro na população, estimando-se que seja até duas vezes e meia mais frequente do que a da anemia, atingindo aproximadamente 4 bilhões de pessoas no mundo ${ }^{5}$.

No Brasil, a anemia por deficiência de ferro constitui importante problema de saúde pública, uma vez que estudos realizados em diferentes cidades revelam prevalências que chegam a afetar mais da metade da população. Inclusive esses estudos mostram que a anemia persiste em patamares elevados ao longo dos anos, especialmente entre as crianças menores de dois anos de idade 6,7,8,9,10,11,12.

Particularmente na infância, a anemia está associada com várias consequências deletérias à saúde, entre elas: diminuição da atividade motora e da interação social, sonolência, irritabilidade e incapacidade de fixar a atenção, atraso no desenvolvimento e alterações comportamentais, bem como o comprometimento do crescimento, alterações metabólicas diversas e anormalidades na pele e mucosas, com prejuízo nos sistemas digestivo e imunológico 13,14,15.

Diante da elevada prevalência e dos inúmeros efeitos adversos em curto e longo prazo dessa doença carencial à saúde das crianças, várias ações de intervenção têm sido adotadas no Brasil, entre elas, a suplementação profilática com sulfato ferroso. A utilização de ferro medicamentoso tem a vantagem de produzir rápidas alterações no estado nutricional de ferro e, além disso, é uma estratégia que pode ser direcionada especificamente aos grupos populacionais com maior risco de desenvolver essa doença ${ }^{16}$. Por esse fato, no Brasil, o Ministério da Saúde adotou desde 2005 a suplementação profilática semanal para crianças menores de dois anos de idade, gestantes e mulheres no período pós-parto, con- forme estabelecido pelo Programa Nacional de Suplementação de Ferro (PNSF) 17.

Embora o PNSF tenha estabelecido a suplementação de $25 \mathrm{mg}$ de ferro elementar uma vez por semana para todas as crianças a partir dos 6 até os 18 meses de idade 17 , não existe consenso na literatura científica no que tange aos melhores esquemas de suplementação (diário ou semanal) ou sobre a dose profilática de ferro elementar que deve ser suplementada na prevenção da anemia.

Assim, o presente estudo teve por objetivo realizar uma revisão sistemática e uma metanálise para comparar a efetividade dos esquemas diários e semanais de suplementação de sulfato ferroso por via oral para profilaxia da anemia ferropriva em crianças com menos de cinco anos de idade. Como objetivos primários foram investigados os efeitos da suplementação sobre a prevalência de anemia e sobre os níveis de $\mathrm{Hb}$, enquanto a avaliação da adesão à intervenção e os possíveis efeitos colaterais do sulfato ferroso foram incluídos como objetivos secundários.

\section{Método}

Para a consecução dos objetivos propostos, procedeu-se uma revisão sistemática da literatura científica no segundo semestre de 2011, buscando-se artigos indexados nas bases eletrônicas da U.S. National Library of Medicine and the National Institutes Health (PubMed), da base Scopus e da Biblioteca Virtual em Saúde (BVS), utilizando referências da Literatura Latino-Americana e do Caribe em Ciências da Saúde (LILACS) e da Scientific Electronic Library Online (SciELO). Além disso, com o objetivo de localizar artigos que não tivessem sido encontrados na busca primária nessas bases, foram checadas manualmente as listas de referências bibliográficas dos artigos selecionados.

Os descritores empregados para a seleção dos estudos, obtidos junto ao DeCS (Descritores em Ciências da Saúde. http://decs.bvs.br) foram: “(criança OR pré-escolar OR lactente) AND anemia AND (prevenção OR suplementação) AND ferro” ou seus equivalentes em inglês,“(child OR preschool OR infant) AND anemia AND (prevention OR supplement) AND iron". Dependendo da base de dados pesquisada, foram usados os termos em português e/ou em inglês, assim como símbolos de truncagem (cifrão ou asterisco) para pesquisar palavras com a mesma raiz, aumentando as chances de detectar um número maior de artigos. A seleção dos estudos foi restrita a artigos publicados entre 1o de janeiro de $1980 \mathrm{e}$ 
31 de dezembro de 2011, e redigidos em inglês, português ou espanhol.

Foram incluídos estudos publicados referentes à faixa etária de crianças menores de cinco anos de idade, por ser essa a faixa etária mais acometida pela deficiência de ferro, especialmente em países de renda média ou baixam, além de estudos de base populacional, como ensaios clínicos randomizados ou não randomizados que investigaram a suplementação com sulfato ferroso, objetivando prevenir ou reduzir a prevalência da anemia.

Foram excluídos da revisão estudos experimentais realizados com animais, aqueles que usaram outros tipos de suplementação diferentes do sulfato ferroso, artigos abrangendo população com mais de cinco anos de idade, estudos relacionando anemia com outras doenças, estudos que investigaram somente crianças anêmicas e/ ou amamentadas exclusivamente até os seis meses, outros artigos de revisão e relatos de caso.

A identificação e a seleção dos artigos foram realizadas por dois pesquisadores de forma independente, que fizeram a seleção inicial pelos títulos dos artigos localizados nas bases de dados e, posteriormente, dos resumos obtidos pela busca eletrônica. Após a seleção inicial, uma nova análise mais criteriosa foi realizada por um terceiro pesquisador, que de forma independente resolveu as discrepâncias e determinou os estudos a serem incluídos na revisão.

Após a seleção dos artigos, procedeu-se à leitura completa dos estudos. Para a extração das informações relevantes dos artigos, foi elaborada uma planilha no programa Microsoft Office Excel 2007 (Microsoft Corp., Estados Unidos) na qual foram registrados os seguintes dados: informações gerais (título, autores, revista, local e ano de publicação do estudo, objetivos e descritores); tipo de estudo de intervenção (ensaio clínico randomizado, não randomizado ou estudo do tipo antes e depois); características da amostra (sexo, faixa etária e tamanho da amostra); características da intervenção (local onde a criança recebeu a suplementação, dose, frequência e tempo de intervenção); critérios de diagnóstico do(s) desfecho(s) e resultados encontrados.

A qualidade de cada artigo foi pontuada de acordo com os critérios de avaliação de Downs \& Black 18 , que consideram 27 itens diferentes divididos em cinco blocos: informações disponíveis (objetivo, tipo de intervenção, desfecho, descrição da amostra, descrição das perdas, variabilidade dos resultados e probabilidade real dos achados), validade externa do estudo (representatividade da amostra, processo de amostragem, representatividade do local e pessoas envolvidas na intervenção), presença de vieses (tipo de ce- gamento, planejamento prévio das análises, duração do acompanhamento em cada grupo, adequação da análise, adesão, acurácia dos testes), controle para fatores de confusão (população de origem dos sujeitos, período de seleção, randomização, cegamento na alocação dos participantes, análises ajustadas, análise por intenção de tratar, perdas consideradas na discussão) e poder do estudo.

Adicionalmente à avaliação de qualidade de Downs \& Black 18, todos os estudos foram também avaliados de acordo com o Quality Assessment Tool for Quantitative Studies do Effective Public Health Practice Project (EPHPP; http:// www.ephpp.ca/Tools.html). A ferramenta desenvolvida pelo EPHPP abrange 22 itens diferentes divididos em oito blocos: viés de seleção, delineamento do estudo, fatores de confusão, cegamento, método de coleta de dados, desistências e abandonos, integridade da intervenção e análises. Cada bloco pode ser classificado como forte, moderado, ou fraco, e, ao final da avaliação, obtém-se um índice total. Usando este ranking de qualidade, cada artigo foi classificado como fraco, moderado ou forte.

Por fim, foram elaboradas tabelas com a síntese descritiva dos artigos incluídos/analisados contendo as seguintes informações: autor, país e ano do estudo, tipo de estudo, população avaliada, tipo de intervenção e dosagem, tempo de intervenção, desfecho avaliado, resultados principais e escore de qualidade obtido segundo Downs \& Black e EPHPP.

Para comparar os efeitos da suplementação com sulfato ferroso sobre a prevalência de anemia e sobre os níveis de $\mathrm{Hb}$, foram realizadas metanálises estratificadas segundo o tipo de suplementação, utilizando o método aleatório para obter as medidas combinadas por conta da heterogeneidade entre os estudos. A heterogeneidade entre os artigos foi definida pelo uso do estatístico $I^{2}$ e do valor de p do teste $\chi^{2}(<0,05)$, e os valores de $I^{2}$ maiores a $75 \%$ foram considerados indicativos de alta heterogeneidade. Na tentativa de explicar a heterogeneidade, foram realizadas metarregressões tendo em conta as covariáveis: dose de sulfato ferroso, duração da intervenção, tipo de estudo de intervenção (ensaio clínico randomizado/não randomizado ou antes-depois), dose total acumulada de ferro, país de origem do estudo (Brasil ou outros países) e qualidade dos artigos (moderado/forte ou fraco). O viés de publicação foi avaliado mediante a construção de gráficos de funil e pelo teste de Egger $(\mathrm{p}<0,05)$. 


\section{Resultados}

As estratégias de busca nas diferentes bases de dados forneceram um total de 10.243 referências (Figura 1). A maioria dos estudos foi excluída após a leitura dos títulos e dos resumos por não corresponder ao tema específico da presente revisão, sendo elegíveis 27 trabalhos para leitura na íntegra. Desses, foram excluídos quatro estudos publicados em outros idiomas (dois em chinês, um em hebraico e um em francês) e outros dez por não cumprirem com os critérios de inclusão (dois por investigar faixas etárias diferentes, cinco por investigar exclusivamente crianças anêmicas, um por investigar crianças amamentadas exclusivamente até os seis meses de idade e dois por investigar outros tipos de suplementação diferentes do sulfato ferroso). Ao final, foram selecionados 13 artigos que atenderam aos critérios de inclusão (estudos que avaliaram a eficácia e/ ou a efetividade de esquemas de suplementação com sulfato ferroso na prevenção da anemia em crianças com até cinco anos de idade), sendo oito estudos brasileiros e cinco oriundos de outros países de renda média ou baixa.
Após a análise de qualidade dos 27 critérios (pontuação máxima possível de 28 pontos), a mediana do escore encontrada nos estudos foi de 18 pontos (amplitude 10-23 pontos). A maioria dos estudos $(69,2 \% ; n=9)$ obtiveram pontuação entre 16 e 20 pontos; sendo $23,1 \%(n=3)$ com pontuação entre 21 e 23 pontos; e 7,7\% $(n=1)$ dos estudos apresentaram pontuação de 10 pontos.

A Tabela 1 apresenta o percentual de acertos para cada um dos critérios do checklist de Downs \& Black.

Dentre os critérios de Downs \& Black, as limitações mais frequentemente encontradas nos estudos foram: problemas com a randomização e cegamento dos participantes, falta de representatividade da população, problemas no ajuste para fatores de confusão, as perdas ao longo do estudo, não apresentação de estimativas do poder do estudo e falta de relato dos efeitos adversos da intervenção. Ao avaliar a qualidade dos artigos de acordo com os critérios da EPHPP, cinco artigos foram classificados como fortes 19,20,21,23,25, um estudo apresentou qualidade moderada 22,23, enquanto os demais foram classificados como fracos.

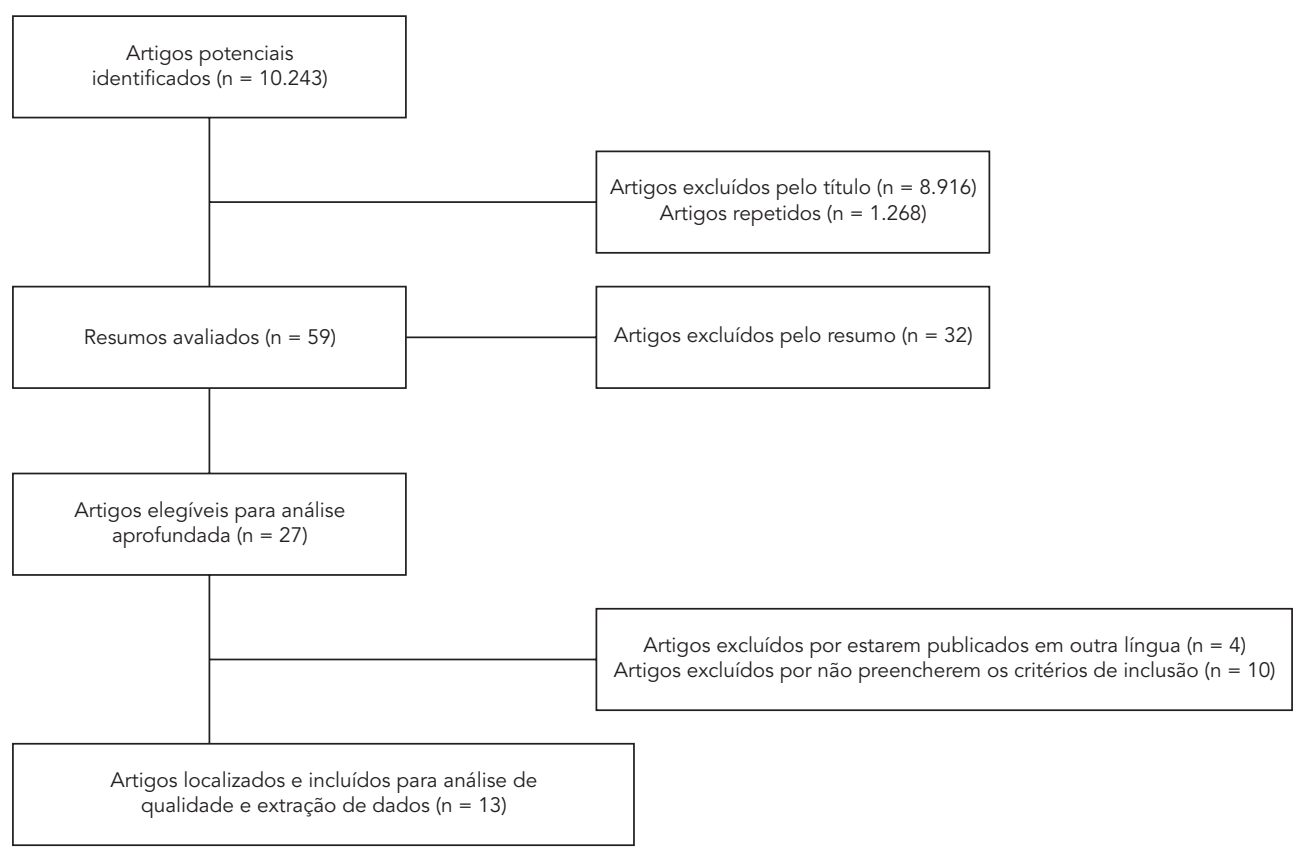


Percentual de acertos dos 27 critérios do checklist de Downs \& Black 18.

\begin{tabular}{|c|c|}
\hline Critério & Acertos $(\%)(N=13)$ \\
\hline \multicolumn{2}{|l|}{ Descrição do estudo } \\
\hline Apresenta hipóteses/objetivos & 100,0 \\
\hline Desfechos bem definidos & 100,0 \\
\hline Critérios de inclusão bem definidos & 61,5 \\
\hline Tipo de intervenção bem definido & 84,6 \\
\hline Descrição clara dos fatores de confusão & 53,9 \\
\hline Principais achados bem descritos & 100,0 \\
\hline Apresenta estimativas de variabilidade dos resultados & 100,0 \\
\hline Relata efeitos adversos da intervenção & 30,8 \\
\hline Descreve as perdas & 46,2 \\
\hline Apresenta intervalo de $95 \%$ de confiança ou valor de $p$ & 100,0 \\
\hline \multicolumn{2}{|l|}{ Validade externa } \\
\hline Sujeitos chamados para o estudo representam a população & 46,2 \\
\hline Sujeitos que participaram do estudo representam a população & 15,4 \\
\hline Lugares/Instalações representativos & 61,5 \\
\hline \multicolumn{2}{|l|}{ Validade interna } \\
\hline Cegamento dos participantes & 7,7 \\
\hline Cegamento dos avaliadores & 84,6 \\
\hline Resultados baseados em dragagem de dados & 100,0 \\
\hline Ajuste para tempo de acompanhamento & 100,0 \\
\hline Testes estatísticos apropriados & 92,3 \\
\hline Adesão confiável às intervenções & 84,6 \\
\hline Medidas acuradas dos desfechos & 76,9 \\
\hline \multicolumn{2}{|l|}{ Viés de seleção } \\
\hline Grupos intervenção/controle recrutados da mesma população & 92,3 \\
\hline Grupos intervenção/controle recrutados ao mesmo tempo & 92,3 \\
\hline Foi realizada randomização & 53,9 \\
\hline Randomização completa e irrevogável & 15,4 \\
\hline Teve ajuste para fatores de confusão & 15,4 \\
\hline Perdas foram consideradas & 53,9 \\
\hline \multicolumn{2}{|l|}{ Poder do estudo } \\
\hline Apresenta o poder do estudo & 23,1 \\
\hline
\end{tabular}

\section{Mudanças nos níveis de hemoglobina}

A Tabela 2 apresenta as principais características e resultados dos 12 estudos que avaliaram a efetividade da suplementação com ferro sobre os níveis de $\mathrm{Hb}$ 19,20,21,22,23,24,25,26,27,28,29,30, considerando a suplementação exclusiva com sulfato ferroso. Todos os estudos foram desenvolvidos em países de renda média ou baixa, sendo sete oriundos do Brasil 19,20,22,23,24,25,26, dois de outros países da América Latina 21,27, dois asiáticos 28,30 e um africano ${ }^{29}$. Das pesquisas brasileiras, somente um estudo 22 envolveu uma amostra populacional representativa, quatro foram desenvolvidas com crianças atendidas em centros de saúde 19,23,24,26 e duas com crianças de creches municipais 20,25. Os estudos de Franco et al. 27 e de Allen et al. 21 incluíram crianças pobres de áreas rurais do Chile e México, respectivamente, enquanto os estudos da Turquia 28 , Gana 29 e Irã 30 foram realizados com crianças atendidas em centros de saúde. Com exceção dos trabalhos de Torres et al. 24, em São Paulo, de Hadler et al. 25, em Goiânia (Goiás), e de Allen et al. 21, no México, nos quais as intervenções duraram 4, 44 e 48 semanas, respectivamente, nos demais estudos o tempo de intervenção oscilou entre 12-32 semanas.

Nove estudos efetuaram suplementação diária (ou na maioria dos dias da semana), usando 
Tabela 2

Estudos que avaliaram a efetividade da suplementação com ferro sobre os níveis de hemoglobina em crianças.

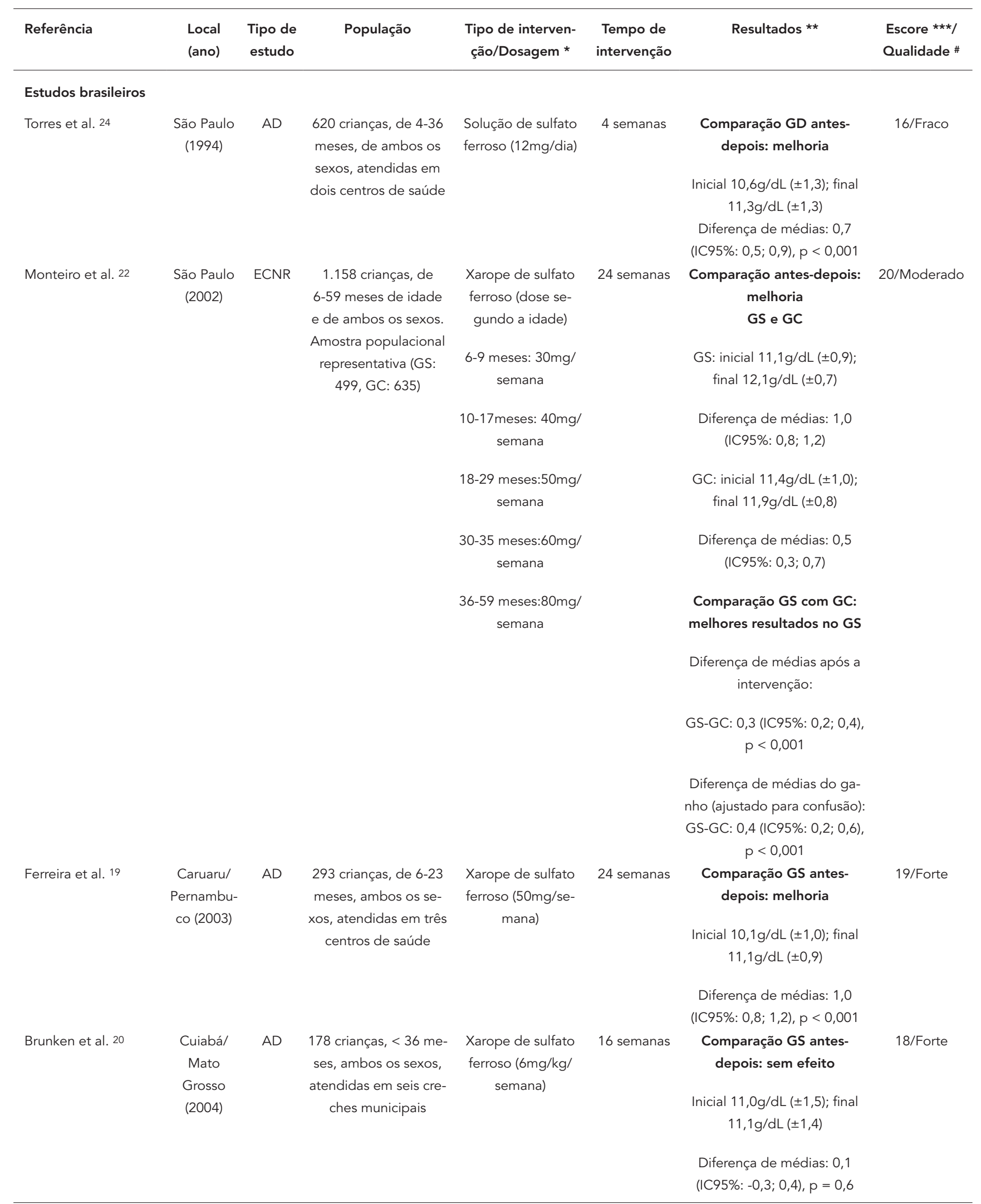

(continua) 
Tabela 2 (continuação)

\begin{tabular}{|c|c|c|c|c|c|c|c|}
\hline Referência & $\begin{array}{l}\text { Local } \\
\text { (ano) }\end{array}$ & $\begin{array}{l}\text { Tipo de } \\
\text { estudo }\end{array}$ & População & $\begin{array}{l}\text { Tipo de interven- } \\
\text { ção/Dosagem * }\end{array}$ & $\begin{array}{l}\text { Tempo de in- } \\
\text { tervenção }\end{array}$ & Resultados ** & $\begin{array}{l}\text { Escore } \star * \star / \\
\text { Qualidade \# }\end{array}$ \\
\hline Engstrom et al. 23 & $\begin{array}{l}\text { Rio de } \\
\text { Janeiro } \\
(2008)\end{array}$ & ECR & $\begin{array}{l}391 \text { crianças de 6-12 } \\
\text { meses de idade e de } \\
\text { ambos os sexos, aten- } \\
\text { didas em centros de } \\
\text { saúde (GD: } 150 \text { crian- } \\
\text { ças, GS: } 147 \text { crianças, } \\
\text { GC: } 94 \text { crianças) }\end{array}$ & $\begin{array}{l}\text { Xarope de sulfa- } \\
\text { to ferroso (GD: } \\
\text { 12,5mg/dia, GS: } \\
\text { 25mg/semana, GC: } \\
\text { sem suplementação) }\end{array}$ & 24 semanas & 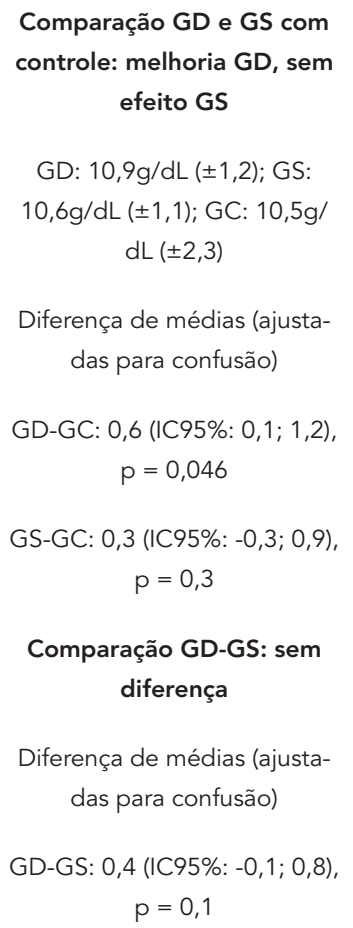 & 23/Forte \\
\hline Hadler et al. 25 & $\begin{array}{c}\text { Goiânia/ } \\
\text { Goiás } \\
\text { (2008) }\end{array}$ & ECR & $\begin{array}{c}219 \text { crianças, 6-24 me- } \\
\text { ses, ambos os sexos, } \\
\text { amostra de } 25 \text { creches } \\
\text { municipais } \\
\text { Crianças com anemia } \\
\quad(\mathrm{Hb}<11 \mathrm{~g} / \mathrm{dL}) \\
\text { GD1: } 43 \text { crianças } \\
\text { Crianças sem anemia } \\
\text { GD2: } 36 \text { crianças }\end{array}$ & $\begin{array}{l}\text { Sulfato ferroso em } \\
\text { gotas } \\
\text { Crianças com ane- } \\
\text { mia } \\
\text { GD1: } 4,2 \mathrm{mg} / \mathrm{kg} / \mathrm{dia} \\
\text { Crianças sem anemia } \\
\text { GD2: } 1,4 \mathrm{mg} / \mathrm{kg} / \mathrm{dia}\end{array}$ & 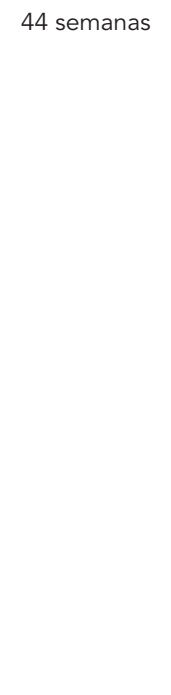 & $\begin{array}{l}\text { Comparação GD antes-de- } \\
\text { pois: melhoria, especialmen- } \\
\text { te em crianças com anemia } \\
\text { Crianças com anemia } \\
\text { GD1: inicial } 9,9 \mathrm{~g} / \mathrm{dL}( \pm 0,7) \text {; } \\
\text { final } 11,3 \mathrm{~g} / \mathrm{dL}( \pm 0,8) \\
\text { Diferença de médias: } 1,3 \\
\text { (IC95\%: } 0,9 ; 1,7), \mathrm{p}<0,001 \\
\text { Crianças sem anemia } \\
\text { GD2: inicial } 11,8 \mathrm{~g} / \mathrm{dL}( \pm 0,6) \text {; } \\
\text { final } 12,1 \mathrm{~g} / \mathrm{dL}( \pm 0,9) \\
\text { Diferença de médias: } 0,3 \\
\text { (IC95\%: } 0,0 ; 0,6), p=0,07\end{array}$ & 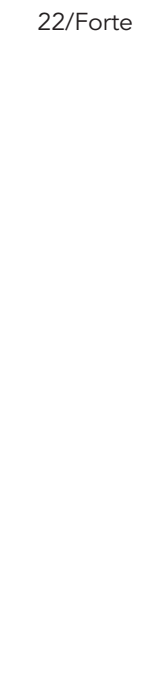 \\
\hline
\end{tabular}

(continua)

doses fixas de 6-20mg/dia 21,23,24,29, de 40-50mg/ dia 29,30 ou segundo o peso $(1-2 \mathrm{mg} / \mathrm{kg} / \mathrm{dia})$ 25,26,27,28. Em sete estudos 21,23,24,25,27,28,30 houve melhoria nos níveis de $\mathrm{Hb}$ e, quando comparados com o período pré-intervenção ou em relação ao grupo controle, tiveram aumento de $0,3-1,0 \mathrm{mg} /$ dL. O estudo realizado em Gana 29 não mostrou melhoria nos níveis de $\mathrm{Hb}$ com nenhuma das du- as doses usadas (12,5 ou 40,0mg/dia) em relação ao grupo controle, enquanto o estudo realizado em Viçosa (Minas Gerais) 26 evidenciou redução de $0,7 \mathrm{mg} / \mathrm{dL}$ nos níveis médios de $\mathrm{Hb}$ em relação ao período pré-intervenção.

Seis dos estudos realizaram suplementação semanal com sulfato ferroso 19,20,22,23,26,30. Ao comparar os resultados pré e pós-intervenção, 
Tabela 2 (continuação)

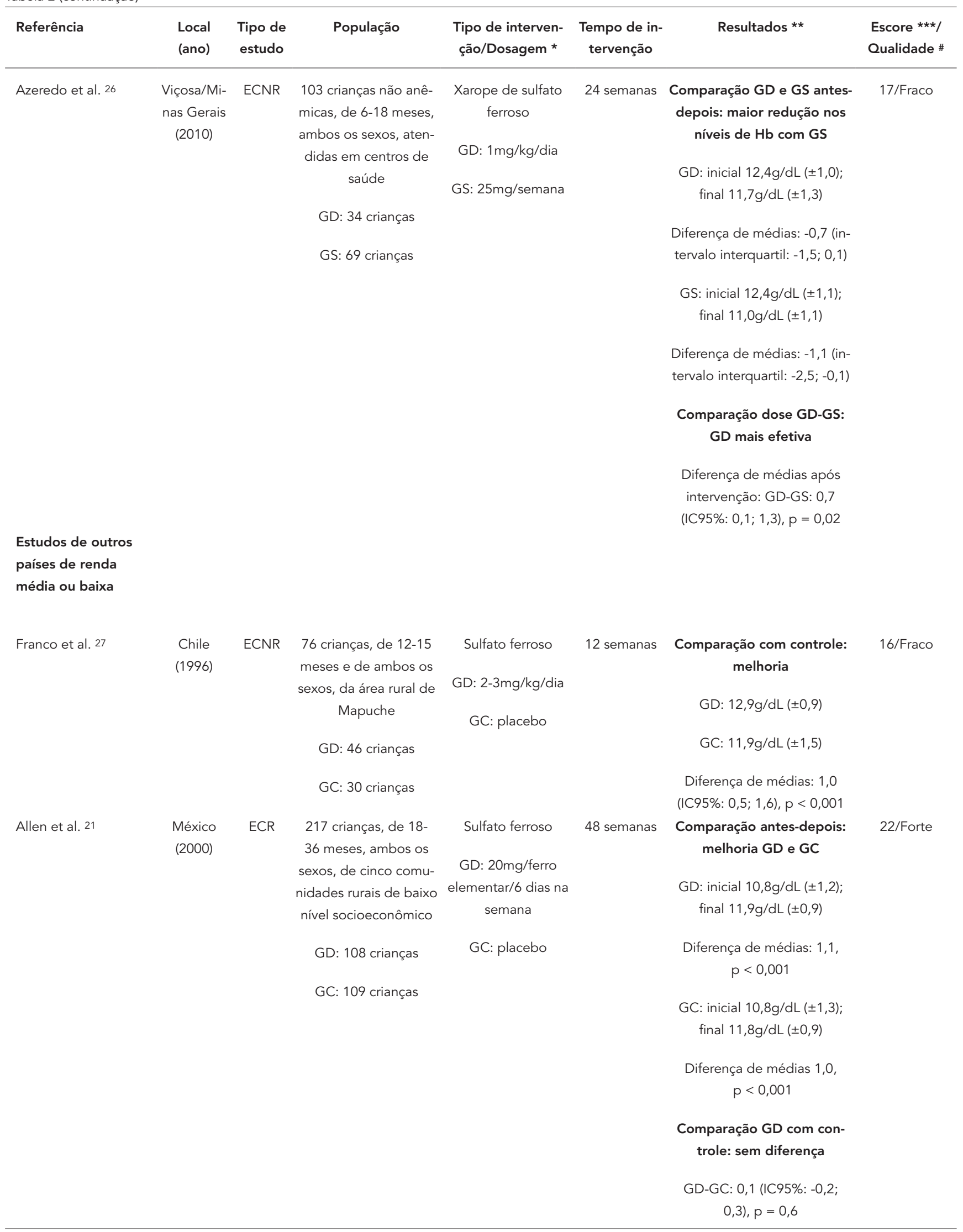

(continua) 
Tabela 2 (continuação)

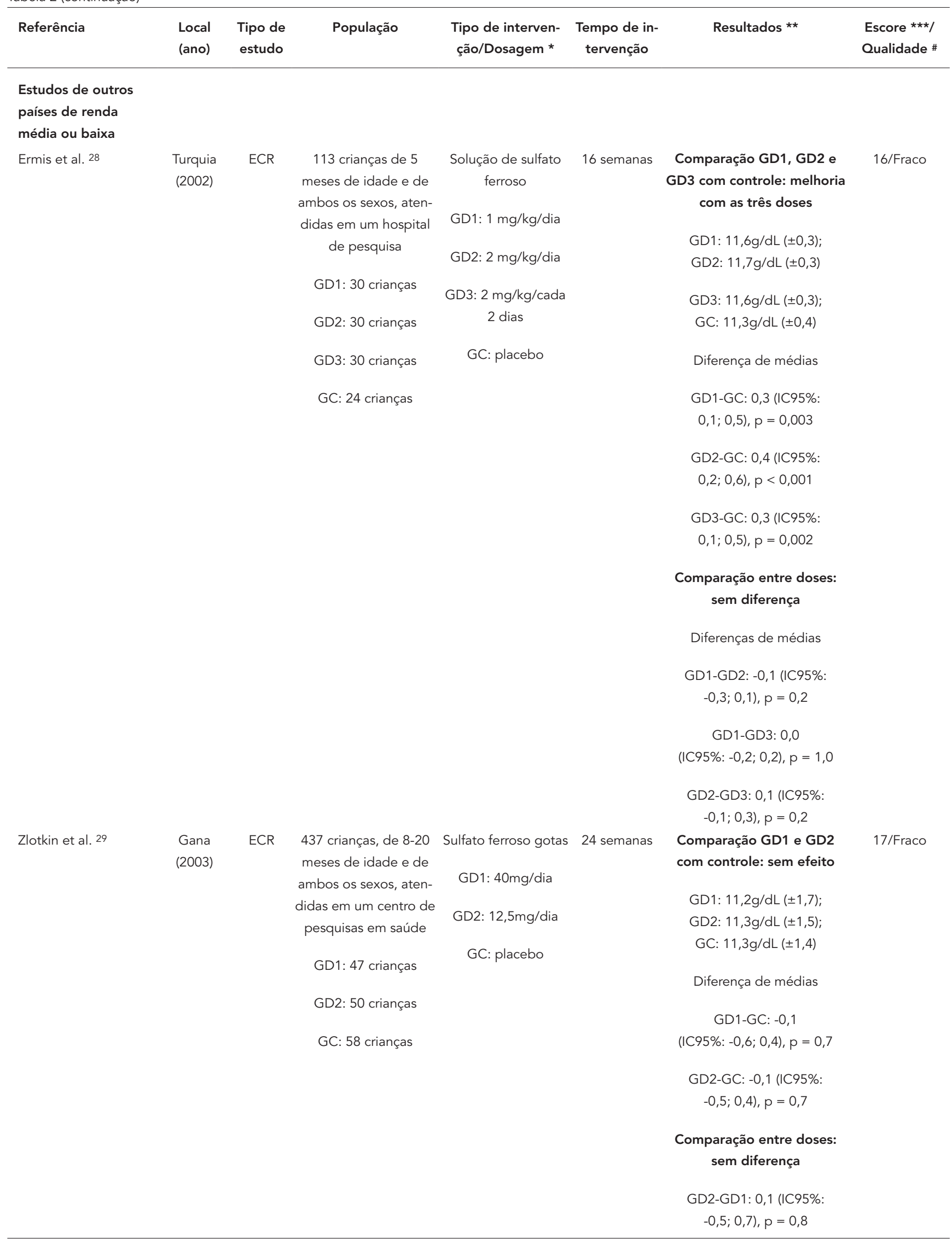

(continua) 
Tabela 2 (continuação)

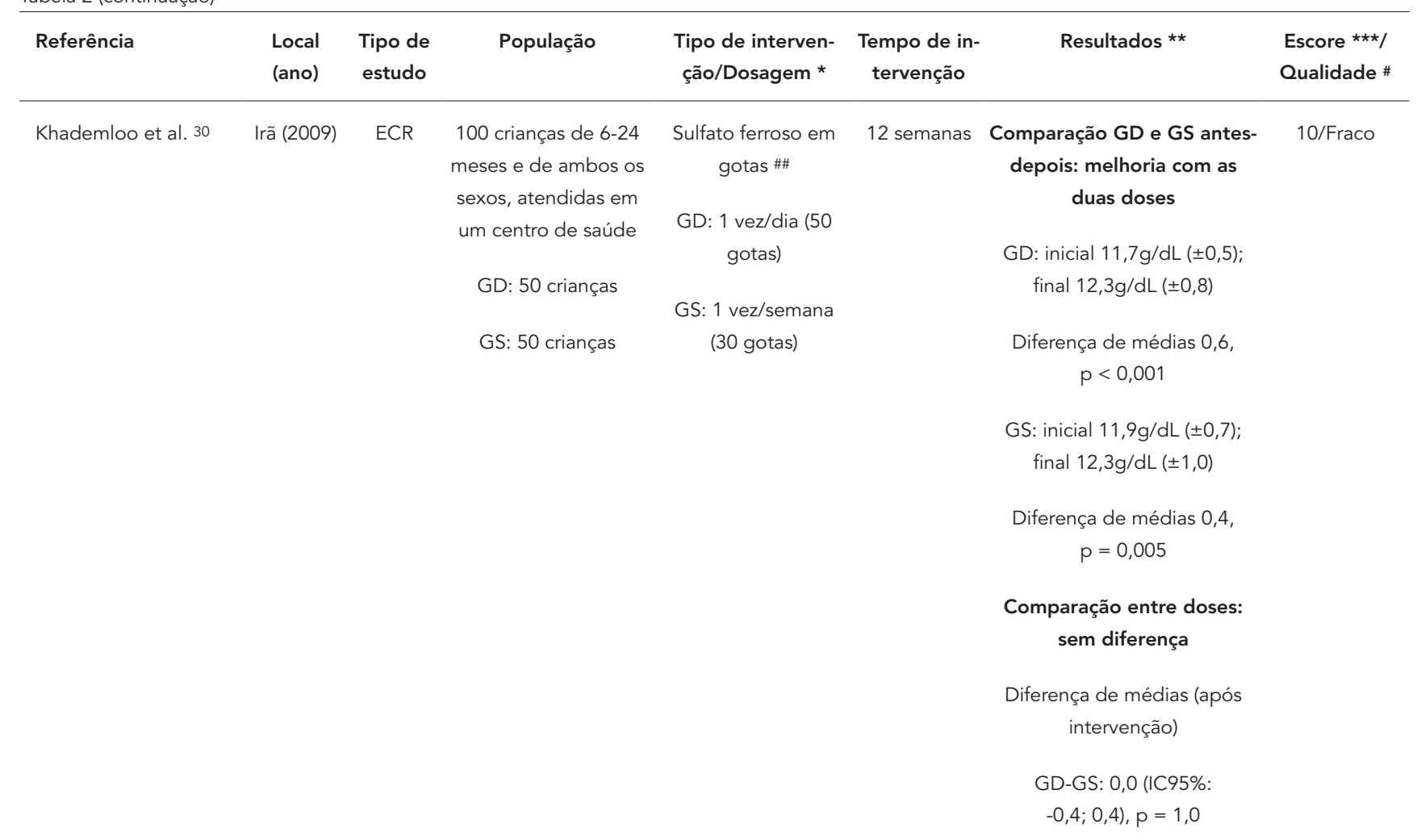

AD: estudo do tipo Antes e Depois; ECNR: ensaio clínico não randomizado; ECR: ensaio clínico randomizado; GC: grupo controle; GD: grupo diário;

GS: grupo semanal; $\mathrm{Hb}$ : hemoglobina; IC95\%: intervalo de $95 \%$ de confiança.

* Os valores de ferro administrado referem-se à mg de ferro elementar;

** Os valores de hemoglobina são apresentados em média \pm desvio padrão;

*** Escore de qualidade segundo Downs \& Black 18;

\# Qualidade dos estudos segundo o Quality Assessment Tool for Quantitative Studies da EPHPP (http://www.ephpp.ca/Tools.htm);

\#\# Não especifica a dosagem, embora a posologia usual seja 1 gota $=1 \mathrm{mg}$ ferro elementar.

dois estudos brasileiros que administraram, segundo a idade da criança, doses fixas de 30$80 \mathrm{mg}$ de sulfato ferroso durante 24 semanas (aproximadamente $5 \mathrm{mg} / \mathrm{kg} / \mathrm{semana}$ ), evidenciaram melhoria nos níveis de $\mathrm{Hb}$ de $1 \mathrm{mg} / \mathrm{dL} 19,22$. No estudo iraniano de Khandemloo et al. ${ }^{30}$, a dose de ferro foi de 30 gotas (aproximadamente $3-4 \mathrm{mg} / \mathrm{kg} / \mathrm{semana}$ ), o que ocasionou melhoria de $0,4 \mathrm{mg} / \mathrm{dL}$ nos níveis de $\mathrm{Hb}$. Por sua vez, estudo realizado com crianças em Cuiabá (Mato Grosso) 20, utilizou uma dose maior de ferro (6mg/ $\mathrm{kg} / \mathrm{semana})$, mas durante um período menor (16 semanas), não encontrando melhorias nos níveis de Hb. Pesquisa realizada em Viçosa 26 utilizou dose semanal de ferro menor (25mg/ semana, equivalente a $2-3 \mathrm{mg} / \mathrm{kg} / \mathrm{semana}$ ), e verificou redução de 1,1mg/dL após a suplementação. Por sua vez, pesquisa realizada no Rio de Janeiro 23 (dose de 25mg/semana), comparando a dose semanal com o grupo controle, observou-se um incremento nos níveis de $\mathrm{Hb}$ de
$0,3 \mathrm{mg} / \mathrm{dL}$, mas esse resultado não foi estatisticamente significativo.

Dois estudos brasileiros 23,26 e um estudo iraniano 30 compararam os efeitos da administração de sulfato ferroso diário e semanal. No estudo realizado no Rio de Janeiro ${ }^{23}$, não foram encontradas diferenças entre os dois tipos de intervenção, embora, quando comparado com o grupo controle, somente a dose diária tenha mostrado efeitos benéficos sobre os níveis de $\mathrm{Hb}$. Já no estudo realizado em Viçosa 26, a dose diária ocasionou menor redução nos níveis de $\mathrm{Hb}$ do que a dose semanal, enquanto no estudo iraniano 30 não houve diferença nos resultados entre os dois tipos de intervenção.

Os resultados da metanálise que comparou os tipos de intervenção mostraram que o efeito combinado das 14 análises que usaram doses diárias apresentou melhoria nos níveis médios de Hb de 0,56mg/dL (IC95\%: 0,31; 0,81, p < 0,001 ), valor esse duas vezes superior ao encon- 
Metanálise de estudos que investigaram os efeitos da suplementação de sulfato ferroso sobre os níveis de hemoglobina sérica. Estratificados segundo esquema de intervenção (diário ou semanal).

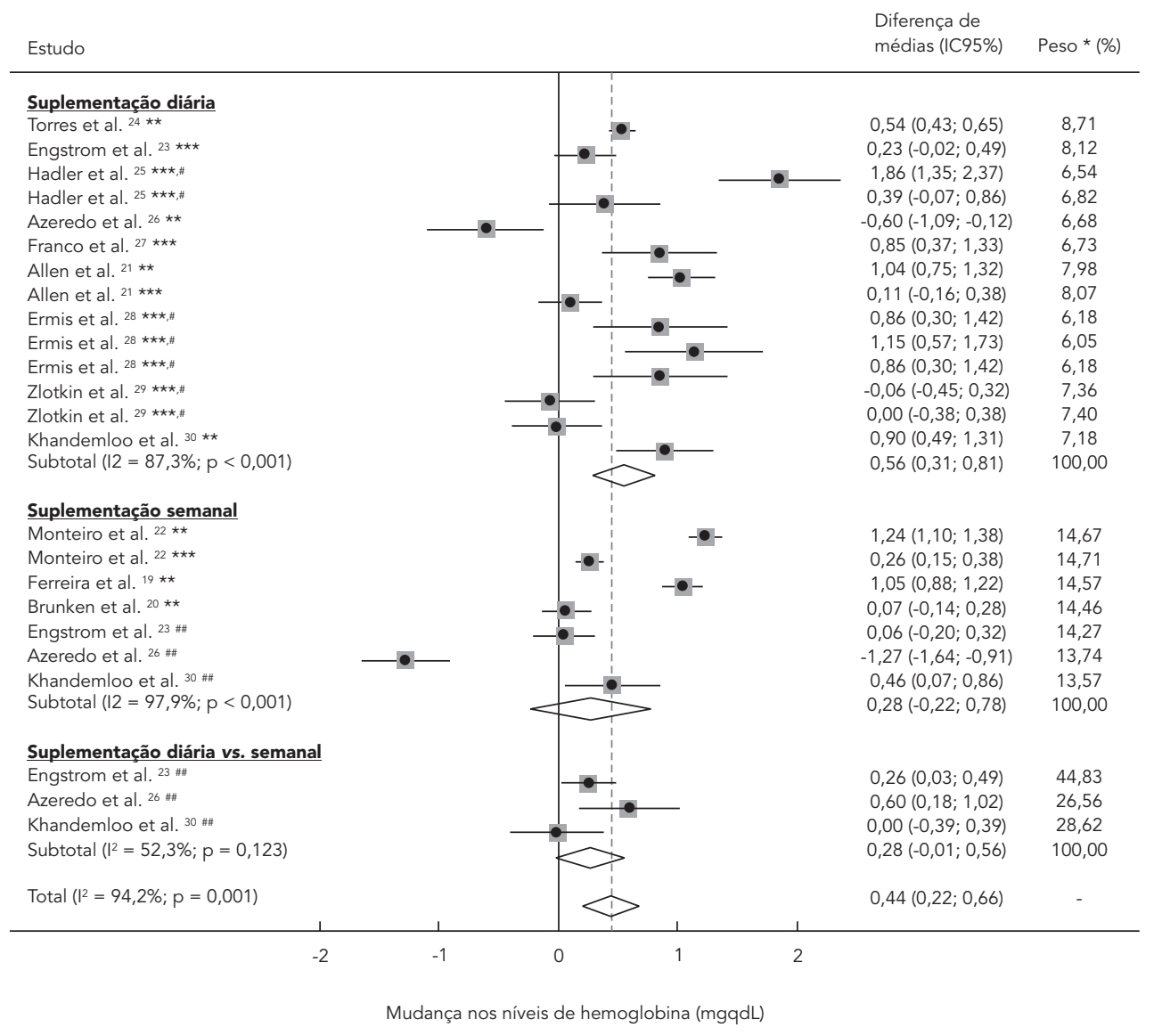

IC95\%: intervalo de 95\% de confiança.

* Pesos baseados em análise de efeitos aleatórios;

** Análise do tipo antes-depois;

*** Grupo intervenção comparado com controle ou placebo;

\# Estudos incluindo amostras que receberam doses diferentes de sulfato ferroso para um mesmo tipo de esquema;

\#\# Grupo diário em comparação com grupo semanal.

trado com as doses semanais (efeito combinado de sete análises $0,28 \mathrm{mg} / \mathrm{dL}$; IC95\%: $-0,22 ; 0,78$, $\mathrm{p}=0$,273) (Figura 2). O resultado combinado das doses diárias em comparação com as semanais também se mostrou favorável ao primeiro tipo de esquema, com nível de significância estatística limítrofe $(0,28 \mathrm{~g} / \mathrm{dL}$; IC95\%: $-0,01 ; 0,56, \mathrm{p}=$ 0,057). Embora não fossem encontradas evidências de viés de publicação pelo gráfico de funil ou pelo teste de Egger (valores de p = 0,22; = 0,31 e= 0,95 , respectivamente), ocorreu evidência de alta heterogeneidade nos estudos que compararam as doses diária e semanal com controle/placebo ( $I^{2}$ superior a $75 \%$ e p $<0,001$ em ambos os casos). Nenhuma das covariáveis incluídas na metarregressão explicaram estatisticamente a heterogeneidade existente entre os artigos (todos com valor de $\mathrm{p}>0,05$ ).

\section{Mudanças na prevalência de anemia}

Quatro estudos brasileiros 20,23,26,31 e um estudo mexicano 21 avaliaram como desfecho a prevalência de anemia, com suplementação diária 
ou semanal durante um período de pelo menos 16-48 semanas (Tabela 3). Nenhum dos três estudos que administraram doses diárias de sulfato ferroso 21,23,31 encontraram melhoria estatisticamente significativa em comparação com o grupo controle, ainda que em todos eles as prevalências fossem menores entre os suplementados. Já com a suplementação semanal, o estudo de Engstrom et al. 23 no Rio de Janeiro não apresentou diferença em relação ao grupo controle, enquanto no estudo de Brunken et al. ${ }^{20} \mathrm{em}$ Cuiabá (Mato Grosso) a prevalência de anemia após a intervenção foi menos da metade do valor pré-intervenção.

Comparando os dois tipos de intervenção, tanto o estudo de Engstrom et al. 23 no Rio de Janeiro, quanto o de Azeredo et al. 26 em Minas Gerais encontraram menor prevalência de anemia com a dose diária de sulfato ferroso do que com a dose semanal, mas somente o segundo estudo apresentou resultados estatisticamente significativos.

Comparando os dois tipos de intervenção em uma metanálise, nem as doses diárias (efeito combinado RP = 0,73, IC95\%: 0,49; 1,09, $\mathrm{p}=0,13$ ) nem as semanais (efeito combinado $\mathrm{RP}=0,64$, IC95\%: 0,27; $1,54, \mathrm{p}=0,33$ ) mostraram efetividade na profilaxia da anemia ferropriva em crianças menores de cinco anos de idade (Figura 3). Também não existiu diferença quando combinados os resultados dos dois estudos que compararam o esquema diário com o semanal (efeito combinado RP = 0,70, IC95\%: 0,41; 1,19, $\mathrm{p}=0,09)$. Não foram encontradas evidências de viés de publicação ( $\mathrm{p}=0,32$ pelo teste de Egger). Novamente houve evidência de alta heterogeneidade nos dois primeiros esquemas comparados (I2 superior a 75\% e p $<0,001$ com ambos), mas nenhuma das covariáveis analisadas na metarregressão conseguiu explicar essa heterogeneidade ( $p>0,05$ para todas as covariáveis).

\section{Suplementação de sulfato ferroso com outros micronutrientes}

A Tabela 3 também apresenta os resultados de dois estudos que compararam a suplementação de sulfato ferroso com e sem a administração de outros micronutrientes. O estudo de Zlotkin et al. 29, realizado em Gana, combinou uma dose de $40 \mathrm{mg} /$ dia de sulfato ferroso com vitamina A, e não encontrou diferenças nos níveis de $\mathrm{Hb}$ quando comparado com a administração exclusiva de ferro (40mg/dia ou 12,5mg/dia). Resultado semelhante foi verificado no estudo brasileiro de Hadler et al. ${ }^{25}$, que suplementou ácido fólico junto à dose de sulfato ferroso, e também não encontrou nenhuma diferença em compara- ção com os grupos que receberam placebo desse micronutriente.

\section{Efeitos colaterais e adesão à suplementação}

Três dos 10 artigos que administraram doses diárias reportaram efeitos colaterais, sendo os principais, vômitos e diarreia 24,29,31. Entre os estudos que administraram doses semanais (seis), apenas o artigo de Brunken et al. 20 relatou os efeitos adversos da intervenção (vômitos e diarreia em $68 \%$ e $33 \%$ dos casos, respectivamente).

Em relação à adesão à suplementação, dois estudos 23,26 compararam os esquemas diário e semanal de suplementação e não encontraram diferenças significativas entre os dois esquemas (a adesão oscilou entre 70-76\%). Um desses estudos mostrou melhoria nos níveis de Hb em relação ao controle, enquanto no outro aconteceu redução desse desfecho, mas inferior ao verificado com a suplementação semanal. Outros dois trabalhos 25,31 que investigaram exclusivamente a efetividade do esquema diário de suplementação encontraram uma adesão de aproximadamente $31 \%$ e acima de $75 \%$, mas nenhum deles identificou benefícios na prevenção da anemia com a suplementação. Entre os estudos com suplementação semanal, somente o realizado por Monteiro et al. 22 investigou esse aspecto, com adesão de 54\% para crianças 6-17 meses de idade e de $64 \%$ para as crianças mais velhas.

\section{Discussão}

Apesar da elevada prevalência da anemia ferropriva em crianças menores de cinco anos, há poucos estudos disponíveis na literatura científica que investigaram a efetividade do sulfato ferroso como medida preventiva para essa doença carencial. A presente revisão sistemática da literatura reuniu todos esses artigos, e três conclusões principais podem ser obtidas com base nas evidências encontradas. Primeiro, independentemente da dose, do tempo de suplementação ou do tipo de comparação realizada (com controle/ placebo ou esquema diário contra semanal), a dose diária de sulfato ferroso mostrou resultados mais consistentes na melhoria dos níveis de Hb do que a administração semanal desse suplemento. Segundo, não foi observada evidência de superioridade ou inferioridade da administração de sulfato ferroso, seja com doses diárias ou semanais, na profilaxia de anemia ferropriva em crianças com menos de cinco anos de idade. E, finalmente, a administração conjunta de outros micronutrientes (vitamina A ou ácido fólico) não revelou benefícios sobre os níveis de $\mathrm{Hb}$ quan- 
Tabela 3

Estudos que investigaram a efetividade do sulfato ferroso sobre a prevalência de anemia em crianças, ou em combinação com outros micronutrientes sobre os níveis de hemoglobina.

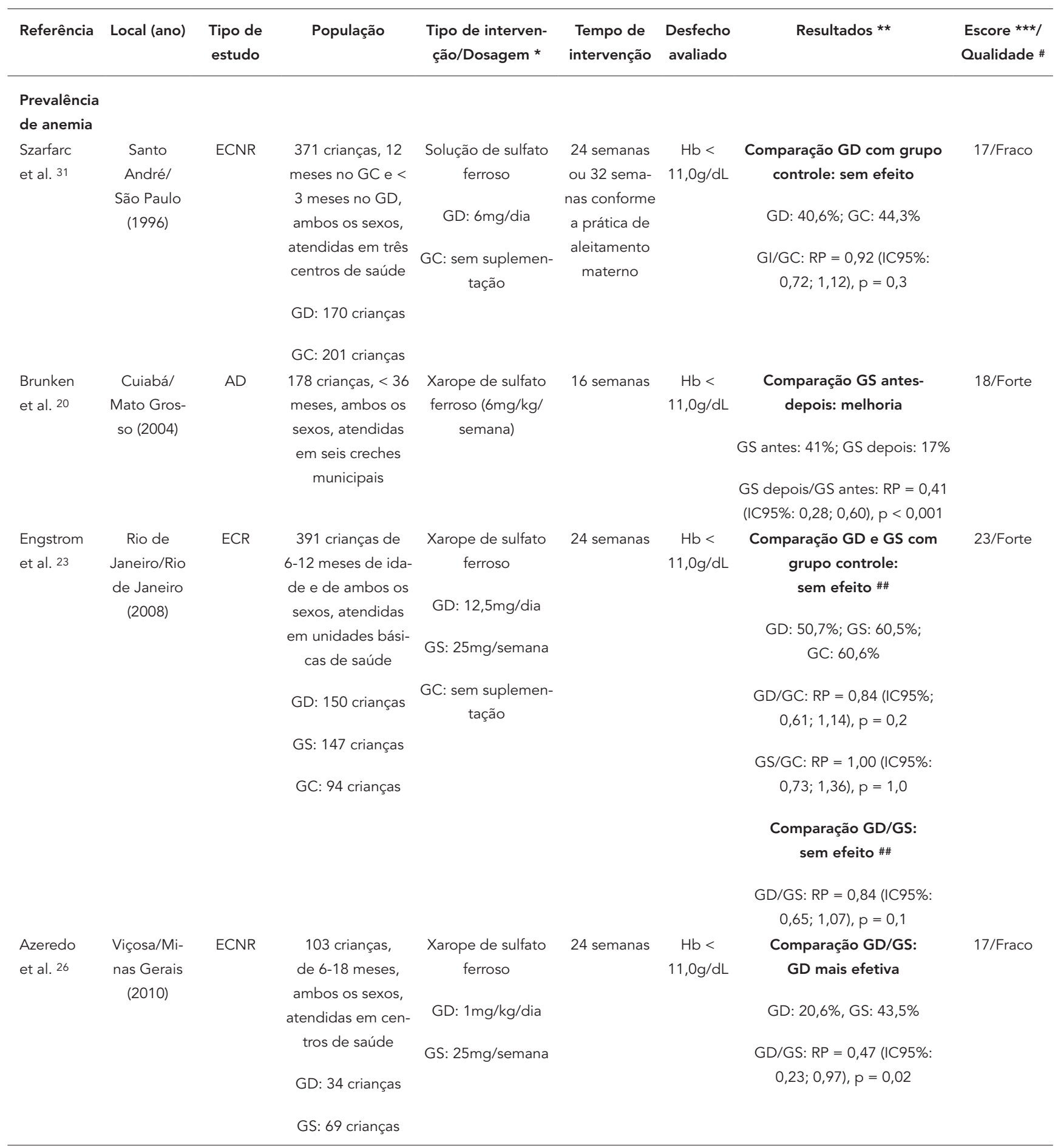

(continua) 
Tabela 3 (continuação)

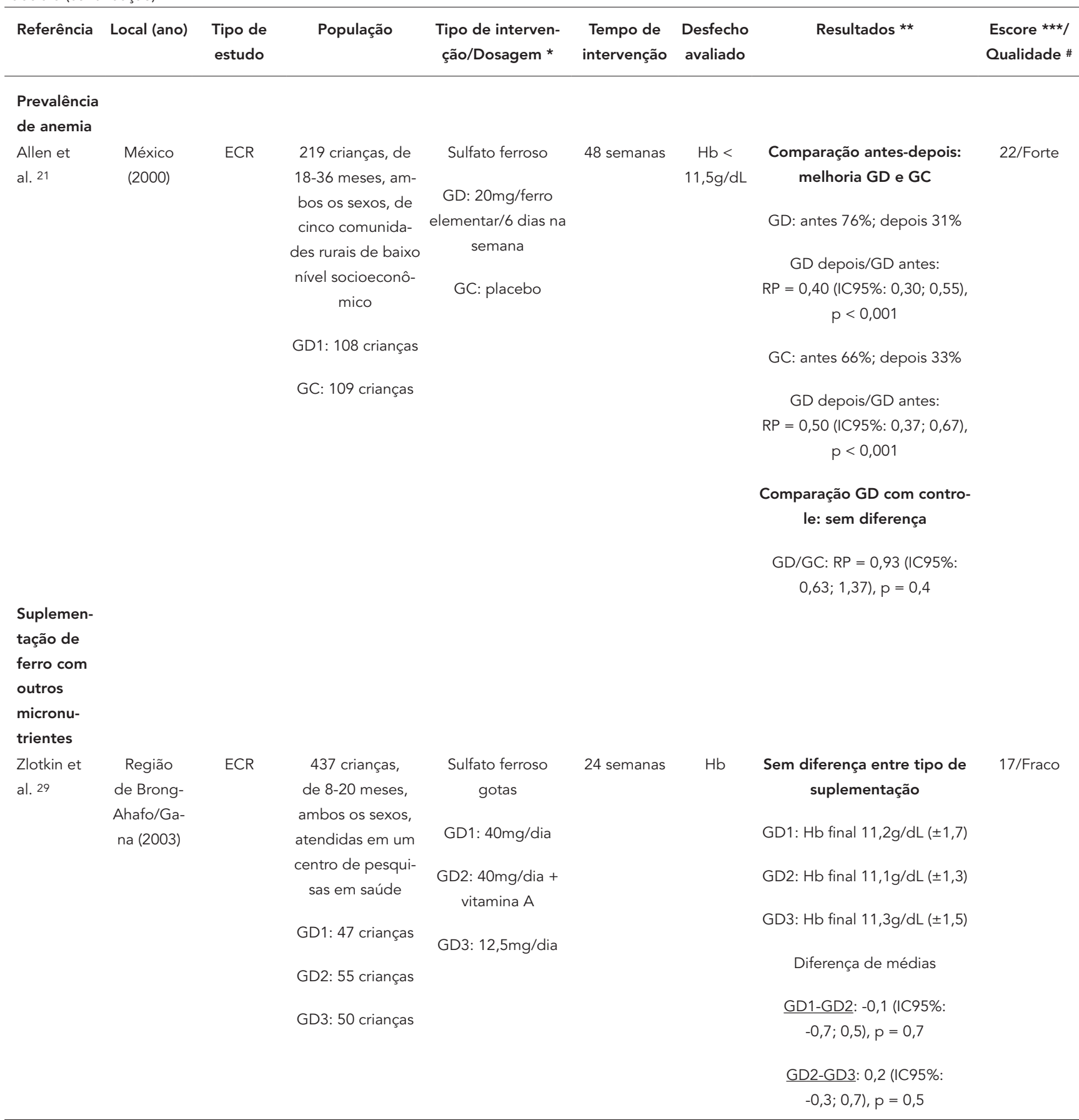

do comparada com a administração exclusiva de sulfato ferroso.

Os benefícios encontrados na melhoria dos níveis de $\mathrm{Hb}$ com a dose diária em comparação com a dose semanal podem resultar do processo fisiológico que envolve a absorção do ferro. Por conta de processos fisiológicos, a absorção do ferro da dieta em indivíduos normais oscila de 5 a $10 \%$, enquanto em indivíduos com deficiência pode atingir $20 \%{ }^{32}$. Nesse processo, algumas diferenças podem ser verificadas no metabolismo do ferro em crianças e em adultos. Enquanto em adultos $95 \%$ das necessidades originam-se da $\mathrm{Hb}$ reciclada, nas crianças, $70 \%$ provêm da reciclagem e o restante da dieta ${ }^{33}$. Além disso, devido ao crescimento rápido com grande expansão da massa celular, dos 4-6 meses de vida ocorre o esgotamento gradual das reservas hepáticas de 


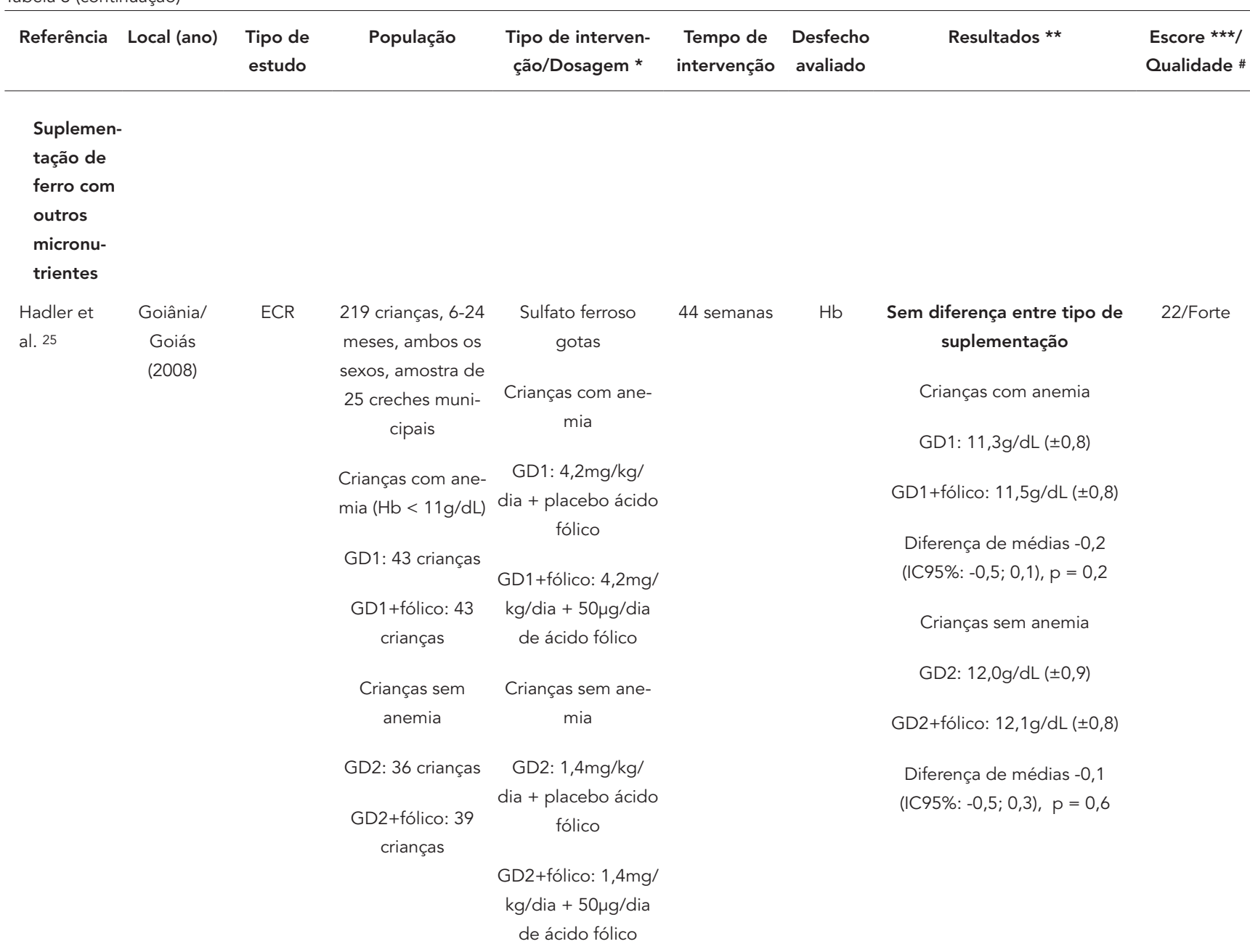

AD: estudo do tipo Antes e Depois; ECNR: ensaio clínico não randomizado; ECR: ensaio clínico randomizado; GC: grupo controle; GD: grupo diário;

GS: grupo semanal; $\mathrm{Hb}$ : hemoglobina; IC95\%: intervalo de $95 \%$ de confiança.

* Os valores de ferro administrado referem-se à mg de ferro elementar;

** Os valores de hemoglobina são apresentados em média \pm desvio padrão;

*** Escore de qualidade segundo Downs \& Black 18;

\# Qualidade dos estudos segundo o Quality Assessment Tool for Quantitative Studies da EPHPP (http://www.ephpp.ca/Tools.htm);

\#\# Valores ajustados para fatores de confusão.

ferro, o que aumenta as necessidades desse mineral. Assim, nos primeiros meses, o aleitamento materno exclusivo propicia ao lactente uma oferta adequada de ferro com elevada biodisponibilidade, o que atende às necessidades fisiológicas da criança nos seis primeiros meses de vida 34,35 . Peculiaridades na alimentação complementar introduzida após essa idade (como a introdução de fitatos dos cereais e a baixa disponibilidade do ferro no leite de vaca) reduzem a biodisponibilidade do ferro para a criança. Dessa forma, por mais que uma dieta balanceada para um adulto forneça os 13-18mg de ferro de que necessita (dos quais somente 1-2mg são absorvidos) 36 , a ali- mentação complementar da criança dificilmente consegue atingir os requerimentos diários, que oscilam de $11 \mathrm{mg} /$ dia em crianças de sete meses a $7 \mathrm{mg} /$ dia em crianças de dois anos 37,38 . Por esses motivos a Sociedade Brasileira de Pediatria recomenda administração profilática de $1 \mathrm{mg} / \mathrm{kg} /$ dia de ferro elementar, iniciando essa suplementação quando a criança passa a receber alimentação complementar e permanecendo até os dois anos de vida (equivalente a aproximadamente 6-12mg/dia ou 40-80mg/semana para crianças de 6-24 meses) 32 . Logo, as doses profiláticas de até $25 \mathrm{mg}$ /semana de ferro elementar usadas em alguns dos estudos incluídos na 
Metanálise de estudos que investigaram os efeitos da suplementação de sulfato ferroso sobre a prevalência de anemia. Estratificados segundo esquema de intervenção (diário ou semanal).

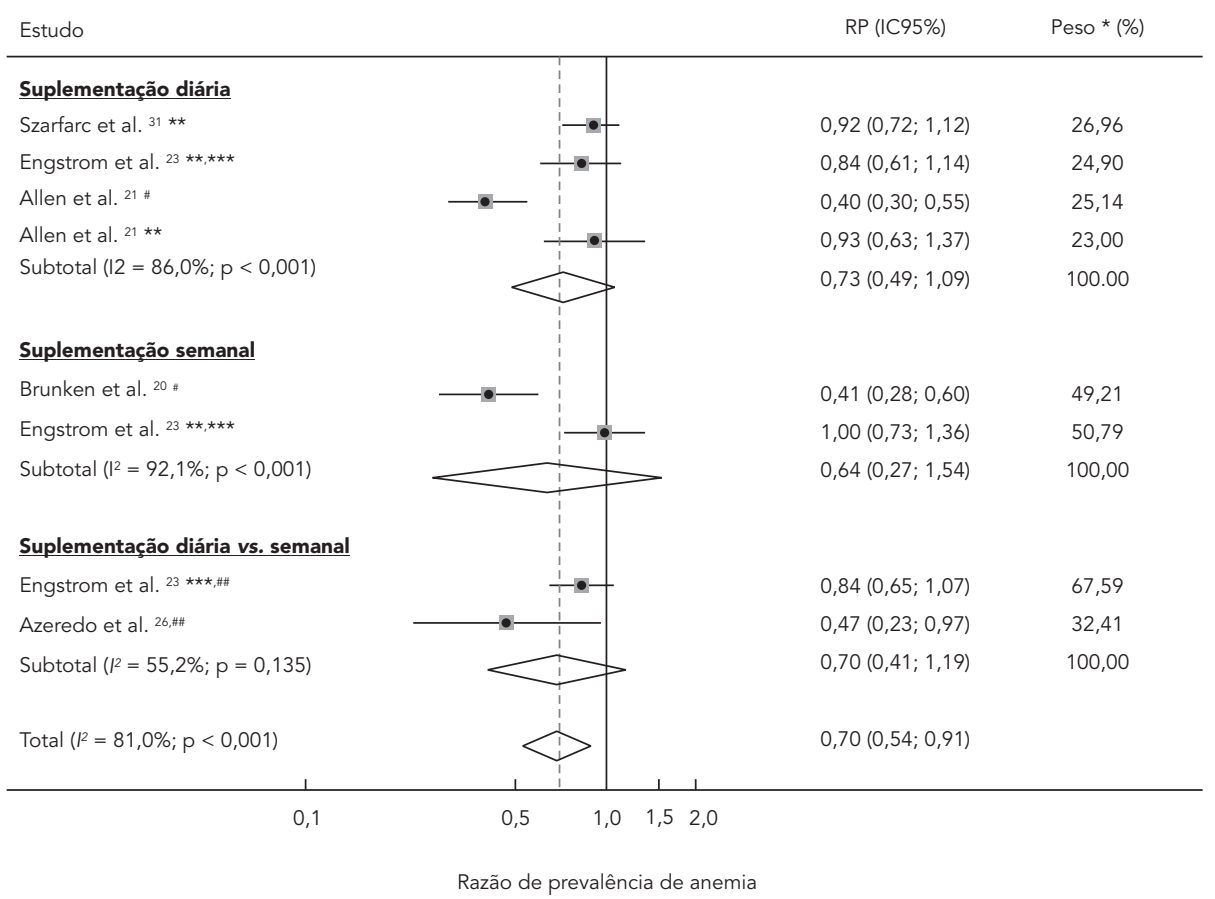

IC95\%: intervalo de 95\% de confiança; RP: razão de prevalência.

* Pesos baseados em análise de efeitos aleatórios;

** Grupo intervenção comparado com controle ou placebo;

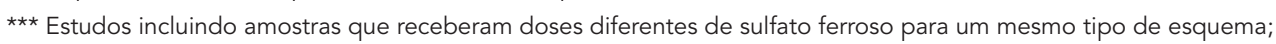

\# Análise do tipo antes-depois;

\#\# Grupo diário em comparação com grupo semanal.

presente revisão 23,26 seriam insuficientes para suprir as necessidades da criança, o que explicaria a menor efetividade observada nesses esquemas. Por sua vez, a efetividade das doses elevadas de ferro administradas semanalmente 19,20,22,30 dependeria da maior absorção desse mineral, o que ocorre somente quando o indivíduo apresenta deficiência de ferro no organismo. Isso explicaria os motivos pelos quais um estudo realizado em Recife (Pernambuco) 39 com menores de dois anos que receberam a suplementação de $25 \mathrm{mg} /$ semana de ferro elementar durante um período de seis meses, tenha encontrado melhoria nos níveis de $\mathrm{Hb}$ somente em crianças com anemia severa (incremento de $0,9 \mathrm{mg} / \mathrm{dL} ; \mathrm{p}<0,001$ ), enquanto entre aquelas com anemia moderada os valores se mantiveram inalterados $(p=1,0)$. Um efeito similar foi constatado no estudo de Hadler et al. 25 , em que somente crianças anêmicas que receberam $4,2 \mathrm{mg} / \mathrm{kg} /$ dia de ferro se beneficiaram com a suplementação.

Outros aspectos relacionados aos hábitos alimentares nos primeiros anos de vida fortalecem ainda mais a recomendação da suplementação diária. A baixa duração do aleitamento materno exclusivo (mediana no Brasil de 54,1 dias) 40, assim como a introdução precoce de produtos processados (de alta densidade energética e com baixa/intermediária biodisponibilidade de ferro) na alimentação complementar da criança contribuem com o declínio dos níveis de $\mathrm{Hb}$ no primeiro ano de vida ${ }^{41}$. De acordo com dados da Pesquisa de Orçamentos Familiares (POF) 33, as famílias brasileiras estão adquirindo cada vez mais alimentos processados, fato que pode repercutir na qualidade da alimentação complementar fornecida às crianças. Além disso, o consumo excessivo de leite de vaca pode interferir na 
absorção do ferro de outros alimentos e provocar a perda de sangue oculto nas fezes, aumentando ainda mais o risco de anemia 42 .

Um dos aspectos que motivou a investigação da efetividade das doses semanais sobre os níveis de $\mathrm{Hb}$ foi a presença dos efeitos adversos relacionados às doses diárias de sulfato ferroso. Entre os estudos avaliados na presente revisão, destaca-se que apenas $4 / 13$ (31\%) relataram a ocorrência de efeitos colaterais decorrentes da suplementação 20,24,29,31, sendo três deles relativos à suplementação diária e apenas um relativo à suplementação semanal. Dessa maneira, as evidências encontradas são insuficientes para garantir que as doses semanais possam estar relacionadas com a menor frequência de efeitos colaterais. No entanto, Yurdakök et al. 43 relataram que a ocorrência de efeitos adversos em lactentes foi similar nos esquemas de suplementação diário e semanal (em torno de 44\%), o que sugere ausência de benefícios de um esquema frente ao outro quanto aos efeitos colaterais da suplementação.

Um segundo aspecto que justificaria o uso da suplementação semanal é a maior adesão ao suplemento. Somente cinco dos estudos incluídos nesta revisão apresentaram algum relato referente à adesão dos participantes à suplementação, os quais mostraram percentuais similares de adesão nos esquemas diário e semanal 22,23,25,26,31. Portanto, além de a dose diária resultar mais efetiva na melhoria dos níveis de $\mathrm{Hb}$ do que os esquemas semanais, tal constatação mais uma vez sugere maiores benefícios desse esquema de suplementação em relação ao esquema semanal.

No caso específico do Brasil, em 2005 o PNSF definiu como estratégia de intervenção a suplementação semanal de $25 \mathrm{mg}$ de ferro elementar ( $5 \mathrm{~mL}$ de xarope de sulfato ferroso) 17 para todas as crianças de 6-18 meses. Essa recomendação foi estabelecida por considera-la uma estratégia efetiva e de custo relativamente baixo, esperando que com doses menores e com maior intervalo se obteria menor percentual de efeitos colaterais e maior adesão. O PNSF considerou como principais referências os estudos de Ferreira et al. 19 e Monteiro et al. 22, que mostraram melhoria nos níveis de $\mathrm{Hb}$ de aproximadamente $1,0 \mathrm{mg} / \mathrm{dL}$ após o término da intervenção. No entanto, esses estudos suplementaram dosagens de sulfato ferroso superiores (de 30-50mg/semana, dependendo da idade da criança) à preconizada pelo PNSF (25mg/semana, independentemente da faixa etária) ${ }^{17}$. Diante deste fato, a recomendação adotada pelo Ministério da Saúde por motivo da implementação do PNSF mostra-se inadequada, inclusive porque dentre dois dos estudos que usaram 25mg/semana para avaliar a efetividade sobre os níveis de $\mathrm{Hb}$, um não mostrou associação 23 e outro apresentou redução desses níveis apenas depois de 24 semanas de suplementação 26. Nesse estudo, realizado por Azeredo et al. 26 , foi comparado o efeito do esquema atual de suplementação recomendado pela Sociedade Brasileira de Pediatria $(1 \mathrm{mg} / \mathrm{kg} /$ dia de ferro elementar) com o preconizado pelo PNSF (25mg/ semana). Após seis meses de suplementação, o grupo que recebeu a dosagem diária apresentou não apenas médias mais elevadas de $\mathrm{Hb}$ em relação ao grupo semanal $(11,7 ; \mathrm{DP}=1,3$ e 11,0; $\mathrm{DP}=1,4$, respectivamente, $\mathrm{p}=0,015$ ), como também foram observadas menores prevalências de anemia no primeiro grupo em relação ao segundo $(20,6 \%$ e $43,5 \%$, respectivamente; $\mathrm{p}=0,04)$.

Sendo assim, o uso de doses menores em intervalos maiores não apresenta o sucesso profilático esperado, o que pode explicar o motivo pelo qual a prevalência de anemia em crianças menores de cinco anos no Brasil se manteve em níveis altos nos últimos anos (prevalências de até $54 \%$ em estudos de base populacional) 6 . A dificuldade em reduzir a prevalência de anemia seria também explicada pela menor efetividade observada com a suplementação profilática de sulfato ferroso sobre esse desfecho. Dos estudos brasileiros, apenas o realizado por Brunken et al. 20 apresentou redução estatisticamente significativa na prevalência da anemia após a intervenção, como também o estudo de Allen et al. 21 realizado com crianças de comunidades rurais de baixo nível socioeconômico no México. Chama a atenção o estudo realizado por Engstrom et al. 23 ter encontrado melhoria significativa nos níveis de $\mathrm{Hb}$, mas não em relação à prevalência da anemia. Isso pode ter ocorrido devido ao tipo de desfecho escolhido (dicotômico), o que reduz o poder do estudo em comparação à avaliação de um desfecho contínuo. Nenhum dos outros estudos que administraram doses diárias de sulfato ferroso encontrou melhoria estatisticamente significativa nas prevalências de anemia em comparação com o grupo controle 21,31, embora em todos eles as frequências da doença fossem menores entre os suplementados.

No que diz respeito à administração conjunta com outros micronutrientes (sulfato ferroso com vitamina A ou ácido fólico), nenhum dos dois estudos incluídos na presente revisão mostraram benefícios da suplementação combinada sobre os níveis de $\mathrm{Hb}$ quando comparados com a administração diária e exclusiva de sulfato ferroso. Embora esses resultados sejam insuficientes para direcionar uma recomendação, eles são consistentes com os de três ensaios clínicos randomizados incluídos em uma metanálise publicada em 2011 por De-Regil et al. 44 que, ao comparar 
a suplementação exclusiva (diária) com fumarato ferroso e a combinada com outros micronutrientes, não encontraram diferenças de efeito sobre a prevalência de anemia ou de deficiência de ferro. Essa metanálise mostrou também que, quando comparada com placebo (ou com controle sem suplementação), a administração caseira de fumarato ferroso com outros micronutrientes reduziu a prevalência de anemia em 31\% (RR = 0,69; IC95\%: 0,60; 0,78) e a deficiência de ferro em $51 \%(R R=0,49$; IC95\%: 0,35; 0,67) 44. Motivado por tais evidências, o Ministério da Saúde brasileiro vem, desde 2011, estudando a possibilidade de aderir à suplementação caseira de ferro juntamente com outros micronutrientes (em pó), como uma forma alternativa ao esquema convencional de suplementação na prevenção da anemia ferropriva em crianças menores de dois anos 45. Mas, com base nos resultados da presente revisão e da metanálise de De-Regil et al. 44, o uso de suplementação diária e exclusiva de ferro parece ser uma medida efetiva com melhor relação custo-benefício para prevenção da anemia, sendo talvez necessário considerar o uso de fumarato ferroso, ou de alguma outra forma de apresentação com maior biodisponibilidade e menor percentual de efeitos colaterais.

Por fim, destacam-se como pontos fortes deste estudo o uso de diferentes bases de dados, a seleção independente dos artigos por duas pesquisadoras (sendo as divergências resolvidas por um terceiro pesquisador), a realização de metanálises para combinar os efeitos dos diferentes estudos e o uso de mais de um critério para a avaliação da qualidade dos artigos. Apesar da disponibilidade na literatura de outros critérios de avaliação da qualidade dos artigos, os dois critérios usados foram consistentes em apontar as limitações metodológicas dos estudos incluídos na revisão. Dentre eles, destacam-se a falta de descrição das perdas dos estudos, a falta de ajuste para essas perdas e para fatores de confusão, a baixa representatividade dos sujeitos do estudo na população e o baixo percentual de artigos que apresentaram o poder do estudo.

A falta de descrição sobre os possíveis efeitos adversos das intervenções também é um item do checklist de Downs \& Black 18 que merece destaque. Apenas quatro estudos 22,23,25,26,31 apresentaram algum comentário sobre os possíveis efeitos adversos das intervenções, como vômitos, náusea, constipação ou diarreia e fezes escurecidas. É importante destacar que as pesquisas de intervenção com sais de ferro devem se preocupar em investigar os possíveis efeitos adversos das intervenções, uma vez que a literatura científica associa a baixa adesão à suplementação aos efeitos colaterais do sulfato ferroso.
Em relação às limitações do estudo, os trabalhos incluídos nesta revisão sistemática apresentaram grande heterogeneidade entre si, especialmente no que se refere às características da população estudada (maior ou menor idade da criança) e na metodologia de intervenção utilizada [periodicidade da suplementação (diária ou semanal), dosagem de ferro, duração da intervenção e o tipo de suplemento usado (apenas sais de ferro ou sua combinação com outros micronutrientes)]. A alta heterogeneidade foi evidenciada estatisticamente nas metanálises realizadas, todavia não foi possível identificar as possíveis fontes dessa heterogeneidade pelo uso de diferentes procedimentos analíticos, incluindo a metarregressão, pela qual os resultados combinados devem ser usados com cautela. Outra possível limitação deste estudo foi a não realização da busca de estudos em outras bases de dados, como EMBASE, Cochrane Central e Web of Science. Ainda assim, mais de uma base em inglês e em português foram usadas na presente revisão, o que reduz a probabilidade de que artigos importantes não tenham sido localizados.

\section{Conclusão}

Os resultados apresentados nesta revisão sistemática sugerem que não há evidências na literatura científica de que as estratégias estudadas de suplementação com sulfato ferroso (seja com dose diária ou semanal) estejam associadas a reduções na prevalência de anemia ferropriva em crianças menores de cinco anos. Por sua vez, os resultados sugerem que a dose diária de sulfato ferroso apresenta benefícios mais consistentes nos níveis de $\mathrm{Hb}$ do que a administração semanal desse suplemento. Os efeitos colaterais e a adesão com ambos os esquemas terapêuticos parecem ser similares, assim a dose diária apresentaria vantagens sobre o esquema semanal. Esses achados dão a entender a necessidade de uma reavaliação dos programas de suplementação profilática que preconizam dosagens semanais de sulfato ferroso, como é o caso do PNSF no Brasil, a fim de utilizar esquemas efetivos na prevenção de anemia entre lactentes. Adicionalmente, resulta fundamental que a suplementação diária seja incorporada a uma estratégia mais ampla que aumente a adesão, incluindo medidas de educação nutricional, o incentivo ao aleitamento materno exclusivo e a conscientização dos envolvidos no cuidado da criança sobre a importância de se prevenir essa doença. 


\section{Resumen}

Revisión sistemática y metaanálisis de estudios que evaluaran la efectividad del suplemento de sulfato ferroso para la prevención de anemia en niños menores de cinco años de edad. Fueron investigadas las bases PubMed, Scopus, SciELO y LILACS e incluidos artículos publicados entre 1980-2011 en español, inglés o portugués, utilizando los unitérminos: niño/niña, preescolar, lactante, anemia, prevención, suplemento e hierro. Fueron seleccionados 13 estudios que mostraron que, independientemente de la dosis y tiempo de toma de suplementos, el esquema diario fue más consistente en la mejoría de los niveles de hemoglobina que el esquema semanal. La toma de suplementos no se mostró efectiva en la reducción de la prevalencia de anemia, inclusive con dosis diarias, y la administración conjunta con otros micronutrientes no trajo beneficios adicionales en comparación con la administración exclusiva del suplemento. La toma de suplementos diarios de sulfato ferroso fue más efectiva que las dosis semanales en la mejoría de los niveles de hemoglobina.

Anemia; Hierro; Preescolar; Suplementos Dietéticos

\section{Referências}

1. World Health Organization. Iron deficiency anaemia: assessment, prevention and control. A guide for programme managers. http://www.who.int/nu trition/publications/en/ida_assessment_preven tion_control.pdf (acessado em 12/Ago/2012).

2. United Nations Children Fund; World Health Organization. Preventing and controlling iron deficiency anaemia in women and children. http:// www.who.int/nutrition/publications/micronutri ents/anaemia_iron_deficiency/e73102/en/index. html (acessado em 10/Ago/2012).

3. Organización Mundial de la Salud. Lucha contra la anemia nutricional, especialmente contra la carencia de hierro. (Serie Informes Técnicos, 580). http://whqlibdoc.who.int/trs/WHO_TRS_580_ spa.pdf (acessado em 13/Ago/2012).

4. World Health Organization. Worldwide prevalence of anaemia 1993-2005: WHO global database on anaemia. http://whqlibdoc.who.int/ publications/2008/9789241596657_eng.pdf (acessado em 12/Ago/2012).

\section{Colaboradores}

F. Cembranel e C. Dallazen estruturaram o conteúdo, analisaram os estudos e redigiram o manuscrito. D. A. González-Chica orientou a redação e fez a revisão do manuscrito.
5. Allen LH, Gillespie SR. What works? A review of efficacy and effectiveness of nutrition interventions. Geneva: Administrative Committee on Coordination/Sub-Committee on Nutrition; 2001. (Nutrition Policy Paper, 19).

6. Vieira RCS, Ferreira HS. Prevalência de anemia em crianças brasileiras, segundo diferentes cenários epidemiológicos. Rev Nutr 2010; 23:433-44.

7. Monteiro CA, Szarfarc SS, Mondini L. Tendência secular da anemia na infância na cidade de São Paulo. Rev Saúde Pública 2000; 36:62-72.

8. Neuman NA, Tanaka OY, Szarfarc SC, Guimarães PRV, Victora CG. Prevalência e fatores de risco para anemia no Sul do Brasil. Rev Saúde Pública 2000; 34:56-63.

9. Lima ACVMS, Lira PIC, Romani SAM, Eickmann SH, Piscoya MD, Lima MC. Fatores determinantes dos níveis de hemoglobina em crianças aos 12 meses de vida na Zona da Mata Meridional de Pernambuco. Rev Bras Saúde Matern Infant 2004; 4:35-43. 
10. Assunção MCF, Santos IS, Barros AJD, Gigante DP, Victora CG. Anemia in children under six: population-based study in Pelotas, Southern Brazil. Rev Saúde Pública 2007; 41:328-35.

11. Ministério da Saúde; Centro Brasileiro de Análise e Planejamento. Pesquisa nacional de demografia e saúde da criança e da mulher 2006: dimensões do processo reprodutivo e de saúde da criança, Estatística e informação em saúde. http://bvsms. saude.gov.br/bvs/pnds/index.php (acessado em 08/Ago/2012).

12. Castro, TG, Nunes MS, Conde WL, Muniz PT, Cardoso MA. Anemia e deficiência de ferro em préescolares da Amazônia Ocidental brasileira: prevalência e fatores associados. Cad Saúde Pública 2011; 27:131-42.

13. Walter T, Olivares M, Pizzaro F, Munhoz C. Iron anemia and infection. Nutr Rev 1997; 55:111-24.

14. Lozoff B. Explanatory mechanisms for poorer developmental in iron deficient anemic infants. In: Black MM, editor. Nutrition health and child development: research advances and policy recommendations. Washington DC: Pan American Health Organization; 1998. p. 162-78.

15. Pollitt E. Early iron deficiency anemia and later mental retardation. Am J Clin Nutr 1999; 69:4-5.

16. Shibukawa AF, Silva EM, Ichiki WA, Strufaldi MWL, Puccini RF. Prophylaxis for iron deficiency anemia using ferrous sulfate among infants followed up at a primary healthcare unit in the municipality of Embu-SP (2003/2004). São Paulo Med J 2008; 126:96-101.

17. Ministério da Saúde. Portaria no 730 de 13 de maio de 2005. Institui o Programa Nacional de Suplementação de Ferro, destinado a prevenir a anemia ferropriva e dá outras providências. Diário Oficial da União 2005; 16 mai.

18. Downs SH, Black N. The feasibility of creating a checklist for the assessment of the methodological quality both of randomized and non-randomized studies of health care interventions. J Epidemiol Community Health 1998; 52:377-84.

19. Ferreira MLM, Ferreira LOC, Silva AA, Batista Filho M. Efetividade da aplicação do sulfato ferroso em doses semanais no Programa Saúde da Família em Caruaru, Pernambuco, Brasil. Cad Saúde Pública 2003; 19:375-81.

20. Brunken GS, Muniz PT, Silva SM. Weekly iron supplementation reduces anemia prevalence by $1 / 3$ in preschool children. Rev Bras Epidemiol 2004; 7:210-9.

21. Allen LH, Rosado JL, Casterline JE, López P, Muñoz E, Garcia OP, et al. Lack of hemoglobin response to iron supplementation in anemic Mexican preschoolers with multiple micronutrient deficiencies. Am J Clin Nutr 2000; 71:1485-94.

22. Monteiro CA, Szarfarc SC, Brunken GS, Gross R, Conde WL. A prescrição semanal de sulfato ferroso pode ser altamente efetiva para reduzir níveis endêmicos de anemia na infância. Rev Bras Epidemiol 2002; 5:71-83.

23. Engstrom EM, Castro IRR, Portela M, Cardoso LO, Monteiro CA. Efetividade da suplementação diária ou semanal com ferro na prevenção da anemia em lactentes. Rev Saúde Pública 2008; 42:786-95.
24. Torres MAA, Sato K, Juliano Y, Queiroz SS. Terapêutica com doses profiláticas de sulfato ferroso como medida de intervenção no combate à carência de ferro em crianças atendidas em unidades básicas de saúde. Rev Saúde Pública 1994; 28:410-5.

25. Hadler MCCM, Sigulem DM, Alves MFC, Torres VM. Treatment and prevention of anemia with ferrous sulfate plus folic acid in children attending daycare centers in Goiânia, Goiás State, Brazil: a randomized controlled trial. Cad Saúde Pública 2008; 24 Suppl 2:S259-71.

26. Azeredo CM, Cotta RMM, Sant'Ana LFR, Franceschini SCC, Ribeiro RCL, Lamounier JA, et al. Efetividade superior do esquema diário de suplementação de ferro em lactentes. Rev Saúde Pública 2010; 44:230-9.

27. Franco E, Hertrampf E, Hazbún J, Segú S, Illanes JS, Palácios L, et al. Iron supplementation in Chilean Mapuche infants of the Cautin Province, Chile. Arch Latinoam Nutr 1996; 46:118-21.

28. Ermis B, Demirel F, Demircan N, Gurel A. Effects of three different iron supplementations in term healthy infants after 5 months of life. J Tropical Pediatr 2002; 48: 280-4.

29. Zlotkin S, Antwi KY, Schauer C, Yeung G. Use of microencapsulated iron (II) fumarate sprinkles to prevent recurrence of anaemia in infants and young children at high risk. Bull World Health Organ 2003; 81:108-15.

30. Khademloo M, Karami H, Ajami A, Yasari M. Comparison of the effectiveness of weekly and daily iron supplementation in 6 to 24 months old babies in urban health centers of Sari, Iran. Pak J Biol Sci 2009; 12:195-7.

31. Szarfarc SC, Berg G, Santos ALS, Souza SB, Monteiro CA. Prevenção de anemia no primeiro ano de vida em centros de saúde do município de Santo André, São Paulo. J Pediatr (Rio J.) 1996; 72:329-34.

32. Departamento de Nutrologia, Sociedade Brasileira de Pediatria. Manual de orientação para a alimentação do lactente, do pré-escolar, do escolar, do adolescente e na escola. 2a Ed. São Paulo: Sociedade Brasileira de Pediatria; 2008.

33. Instituto Brasileiro de Geografia e Estatísticas. Pesquisa de orçamentos familiares no Brasil, 2008/2009. Avaliação nutricional da disponibilidade domiciliar de alimentos no Brasil. Rio de Janeiro: Instituto Brasileiro de Geografia e Estatística; 2010.

34. Dewey KG, Cohen RJ, Rivera LL, Brown KH. Effects of age of introduction of complementary foods on iron status of breast-fed infants in Honduras. Am J Clin Nutr 1998; 67:878-84.

35. Domellof M, Cohen RJ, Dewei KG, Hernell O, Rivera LL, Lonnerdal B. Iron supplementation of breast-fed Honduras and Swedish infants from 4 to 9 months of age. J Pediatr 2001; 138:679-87.

36. Grotto HZW. Fisiologia e metabolismo do ferro Rev Bras Hematol Hemoter 2010; 32 Suppl 2:8-17.

37. Food and Agriculture Organization of the United Nations. Human vitamin and mineral requirements. Rome: Food and Agriculture Organization of the United Nations; 2002. 
38. Food and Nutrition Board, Institute of Medicine. Dietary reference intakes for vitamin A, vitamin K, arsenic, boron, chromium, copper, iodine, iron, manganese, molybdenum, nickel, silicon, vanadium and zinc. http://www.nap.edu/catalog. php?record_id=10026 (acessado em 15/Ago/2012).

39. Eickmann SH, Brito CMM, Lira PI, Lima MC. Efetividade da suplementação semanal com ferro sobre a concentração de hemoglobina, estado nutricional e o desenvolvimento de lactentes em creches do Recife, Pernambuco, Brasil. Cad Saúde Pública 2008; 24 Suppl 2:S303-11.

40. Secretaria de Atenção a Saúde, Ministério da Saúde. II pesquisa de prevalência do aleitamento materno nas capitais e Distrito Federal. http://portal. saude.gov.br/portal/arquivos/pdi/pesquisa_pdf. pdf (acessado em 30/Ago/2012).

41. World Health Organization. Complementary feeding of young children in developing countries: a review of current scientific knowledge. http://www. who.int/nutrition/publications/infantfeeding/ WHO_NUT_98.1/en/ (acessado em 21/Ago/2012).
42. Farias Junior G, Osório MM. Padrão alimentar de crianças menores de cinco anos. Rev Nutr 2005; 18:793-802.

43. Yurdakök K, Temiz F, Yalçin SS, Gümrük F. Efficacy of daily and weekly iron supplementation on iron status in exclusively breast-fed infants. J Pediatr Hematol Oncol 2004; 26:284-8.

44. De-Regil LM, Suchdev PS, Vist GE, Walleser S, Peña-Rosas JP. Home fortification of foods with multiple micronutrient powders for health and nutrition in children under two years of age. Cochrane Database Syst Rev 2011; (9):CD008959.

45. Coordenação Geral de Alimentação e Nutrição, Ministério da Saúde. Fortificação caseira com múltiplos micronutrientes em pó. http://nutricao. saude.gov.br/workshop_fortificacao.php (acessado em 23/Jul/2012).

Recebido em 16/Out/2012

Versão final reapresentada em 03/Mai/2013

Aprovado em 14/Mai/2013 
Cembranel F, Dallazen C, González-Chica DA. Efetividade da suplementação de sulfato ferroso na prevenção da anemia em crianças: revisão sistemática da literatura e metanálise. Cad Saúde Pública 2013; 29(9):1731-1751.

A revista foi informada sobre alguns erros no artigo. As correções seguem abaixo:

The journal has been informed about some errors in the paper. The corrections are follows:

La revista fue informada sobre algunos errores en el artículo. Siguen las correcciones:

- Na página 1734, segunda coluna, linha 20, onde se lê:

...Ao avaliar a qualidade dos artigos de acordo com os critérios da EPHPP, três artigos foram classificados como fortes 19,20,21, dois estudos apresentaram qualidade moderada 22,23 ...

leia-se:

...Ao avaliar a qualidade dos artigos de acordo com os critérios da EPHPP, cinco artigos foram classificados como fortes 19,20,21,23,25, um estudo apresentou qualidade moderada 22 ..

- Na página 1737, Tabela 2, linha "Engstrom et al. 23 ", coluna 8 , onde se lê:

22/Moderado

leia-se:

22/Forte

- Na página 1737, Tabela 2, linha "Hadler et al. 25", coluna 8, onde se lê:

22/Fraco

leia-se:

22/Forte

- Na página 1742 , segunda coluna, linha 6 , onde se lê:

Três dos 10 artigos que administraram doses diárias reportaram efeitos colaterais, sendo os principais, vômitos e diarreia 24,29,31, não havendo nenhuma especificação nesses trabalhos sobre o percentual de crianças que apresentaram tais sintomas.

leia-se:

Três dos 10 artigos que administraram doses diárias reportaram efeitos colaterais, sendo os principais, vômitos e diarreia 24,29,31.
- Na página 1742 , segunda coluna, linha 24 , onde se lê:

...Outros dois trabalhos 25,31 que investigaram exclusivamente a efetividade do esquema diário de suplementação encontraram uma adesão de $31 \%$ e 75\%...

leia-se:

...Outros dois trabalhos 25,31 que investigaram exclusivamente a efetividade do esquema diário de suplementação encontraram uma adesão de aproximadamente $31 \%$ e acima de $75 \%$..

- Na página 1733, Tabela 3, linha "Engstrom et al. 23", coluna 9, onde se lê:

22/Moderado

leia-se:

22/Forte

- Na página 1745, Tabela 3, linha "Hadler et al. 25", coluna 9, onde se lê:

22/Fraco

leia-se:

22/Forte

- Na página 1748, primeira coluna, linha 52, onde se lê:

...Apenas cinco estudos 22,23,25,26,31 apresentaram algum comentário sobre os possiveis efeitos adversos das intervenções...

leia-se:

...Apenas quatro estudos 20,24,29,31 apresentaram algum comentário sobre os possíveis efeitos adversos das intervenções... 